\title{
NEXT TO PRODUCTION OR TO TECHNOLOGICAL CLUSTERS? THE ECONOMICS AND MANAGEMENT OF R\&D LOCATION
}

\author{
Myriam Mariani \\ MERIT, University of Maastricht, Maastricht (The Netherlands) \\ email:m.mariani@merit.unimaas.nlormymarian@tin.it
}

Key-words: Geography of R\&D - Innovation - Management of R\&D - R\&D - Technological external economies.

\begin{abstract}
This paper examines the relationship between the location of R\&D and production activities. By using a sample of 799 Japanese investments in Europe, it distinguishes between affiliates performing only $R \& D$, both $R \& D$ and production, and production only. The analysis produces two main results. First, $R \& D$ tends to locate near production activities. Interestingly, however, the higher the science-intensity of a sector, the less important is the linkage with production - i.e. the higher the number of only $R \& D$ labs. This is interpreted as the effect produced by more general and transferable scientific work, compared to applied work. Second, by performing a multinomial logit analysis, we show that $R \& D$ independent or linked to production are attracted by different local factors. Managerial and policy implications are also discussed.
\end{abstract}

\section{Introduction}

This paper examines two seemingly conflicting phenomena: the globalisation of research and the regional clustering of innovative activities. Both trends have been at the core of recent work in the literature. Studies on the geography of innovation have highlighted the increasing clustering of technological activities (e.g. Audretsch and Feldman, 1996). Others have pointed out that globalisation has increased because firms are spreading research facilities across several countries (e.g. Florida, 1997). Still others have argued that, when international technology strategies are chosen according to the comparative advantages of different countries, there is not a real dichotomy between globalisation and regionalisation (e.g. Cantwell, 1991; Archibugi and Michie, 1995).

The key to understanding the analysis of this paper is that in developing innovations a trade-off exists between the benefits of spreading research close to 
production, and the advantages of concentrating it in the areas with technological external economies. Several classical studies point out that innovation depends on systematic relationships with markets or manufacturing operations (e.g. Rosenberg, 1982). This suggests that innovative activity, including $R \& D$, ought to be located near the users or the production facilities, and therefore tends to be spread in different areas. But R\&D and innovation also benefit from technological external economies, and other supply-side factors for knowledge creation, which are often geographically concentrated. By locating according to these factors, R\&D would concentrate in fewer regions.

The goal of this paper is to better understand this trade-off. To do so, it studies the factors that encourage a separation between $R \& D$ and production, and those that call for proximity between $R \& D$ and manufacturing operations. It shows that, among other things, the possibility of separating $R \& D$ from production is influenced by the scientific content of the research performed. The paper also studies the regional factors - technological external economies -- that lead to the concentration of R\&D separated from manufacturing, and discusses some managerial and policy implications.

The paper uses data on Japanese R\&D and production investments in Europe. Although the study of Japanese foreign investments might be interesting per sé, this is not a paper about Japan. We use the Japanese data as a means to describe more general trends in the location of research. The reason to do so is twofold. First, Japanese R\&D investments in Europe can be considered "exogenous" with respect to the technological endowment of the regions. Because they account for a relatively small share of investments in each region, they do not determine the R\&D intensity and the specialisation of the regions themselves. Thus, one does not run into the problem that the R\&D investments of these companies are themselves the determinants of the technological endowment of the areas (which might be the case for the localisation of R\&D labs by European firms in Europe). Second, the Japanese External Trade Organisation (Jetro) issues a special survey on Japanese European R\&D and manufacturing operations. By the end of 1995 the Jetro survey on 799 Japanese investment facilities in Europe specifies whether the European facility is an independent $\mathrm{R} \& \mathrm{D}$ lab, and independent manufacturing operation, or a manufacturing 
operation with an associated $\mathrm{R} \& \mathrm{D}$ lab. This enables us to examine the factors, and particularly the geographic characteristics of the area wherein the facility is located, that affect the location of $R \& D$ labs linked to production vis-à-vis independent $R \& D$ operations.

Apart from the Jetro survey, the paper employs patent statistics from the European Patent Office, and the EUROSTAT REGIO database to describe the characteristics of economic and innovative activity in the various regions. To examine the relationship between these characteristics and the location of different types of Japanese investments (production, $R \& D$, or joint production and $R \& D$ ) the paper will perform a multinomial logit analysis.

Section 2 briefly discusses some of the literature on the globalisation and regionalisation of innovative activities and the implications of the geography of R\&D for the efficiency of knowledge production and diffusion. Section 3 describes the data and the trends in the location of R\&D. Section 4 and 5 present the econometric model and the estimated results. Section 6 discusses managerial and policy implications. The final section concludes.

\section{The globalisation and the regionalisation of R\&D: A framework.}

Quite a few authors highlighted that countries have narrowed their technological specialisation and that, within countries, economic activity, whether production or innovation, tends to cluster. ${ }^{1}$ In the case of innovation, the benefits from being geographically close are enhanced by the fact that knowledge exchange is influenced by the distance among the economic agents (Jaffe, 1989; Jaffe, Henderson and Trajtenberg, 1993; Caniels, 1997). Audretsch and Feldman (1996) also found that there are sectoral differences in spatial clustering with some industries like computer and pharmaceuticals displaying a higher degree of concentration compared to all manufacturing. Breschi (1995) derived similar conclusions by examining patent data from the European Patent Office during 1978-1991. 
While this process of geographical specialisation and clustering is going on, another phenomenon is taking place, leading to a higher international diffusion of research. Leading international companies are increasingly conducting research abroad. Although some authors indicate that the "global generation of inventions" is still far from being a common behaviour (Patel and Pavitt, 1992), there is evidence of a trend in this direction (Cantwell, 1994). ${ }^{2}$ Many authors, including Pearce and Singh, (1992), Bartlett and Goshal (1990) have highlighted the raise of institutions which organise technology creation on global bases. The traditional literature on this topic suggests that R\&D follows the establishment of production activity, and depicts an international spread of labs according to firms' organisational requirements and to the perceived need to adapt the production to local market conditions (e.g. Gerybadze and Reger, 1997). Drawing advantage from the knowledge they get from the market, they exploit locally innovations that have been developed in the home country. This is consistent with the traditional view of innovation arising from production activities (Rosenberg, 1982).

More recent contributions explored the trend towards the re-localisation of stand-alone R\&D labs in areas offering scientific and technological specialised resources. Florida (1997) carried out a survey of stand-alone foreign laboratories in the United States. He highlighted the importance of technological factors in attracting the localisation of foreign independent laboratories. Other studies have suggested that firms may move research abroad according to "technology-driven" motivations. Since the capability to innovate draws on the environment in which research is carried out, this shift may reflect corporate efforts to harness external economies and to benefit from technological spillovers stemming from localised skills and competencies. ${ }^{3}$ Since these skills and competencies are geographically concentrated, this appears to resolve the seeming contradiction between "globalisation" and "regionalisation".

This paper studies the factors that enable the separation of R\&D from downstream production activities, and its localisation in the agglomeration areas. It argues that there are two necessary conditions for doing so. First, the possibility of separating $R \& D$ from production critically depends upon the scientific content of the 
research performed. And second, there must be some specific regional characteristics in order to attract the set up of $R \& D$ independently of production.

It is commonly known that $\mathrm{R} \& \mathrm{D}$ includes activities with a different degree of scientific content. To simplify one can say that some of them are more science intensive. Others are more directly related to users' applications. They also benefit from different external economies. More user-oriented research would benefit from the proximity to the users and to the manufacturing activity. By contrast, scientific research, whose production is strongly dependent upon elements that are embedded in people, technological structures and places (De Solla Price, 1984), would be performed in the most technologically active areas. This would also avoid the duplication of the investment in the various places wherein the innovation is to be applied. We argue that the separation of more science-intensive R\&D from production can improve this trade-off in the organisation and location of R\&D.

With science-intensive technologies this separation is easier because this type of research often produces generic knowledge or "general purpose technologies" (Bresnahan and Trajtenberg, 1995). Their major characteristic is that knowledge, once produced, is not tied to the organisation and the context in which it is generated, and is quite independent of demand-specific adaptations. This implies that, once an innovation is introduced, it can be used in several applications without having to reinvent the original idea every time. In this sense, generality commands the centralisation of research, and allows for the portability of its results across contexts and distances. The diffusion and application of information produced in a certain place can occur in a large number of locations and organisations although being distant from the source. (See also Arora and Gambardella, 1994.)

It is natural that this separation increases the probability of scientific research being independently located in the areas with the external economies for knowledge production, as Lamoreaux and Sokoloff (1997) have for instance shown in the case of the US in the XIX century. By contrast, more users' oriented research is more likely to located closer to production, and possibly utilise the "general purpose technologies" developed elsewhere. ${ }^{4}$ Moreover, this geographical division of innovative labour could 
increase the efficiency of both types, generic and user-specific, R\&D activities. Eventually, it might lead to a world with a restricted club of countries, regions, and firms that are more efficient in producing the relevant knowledge and a multitude of countries, regions, and firms that have comparative advantages in using and adapting it to their needs. This would also shape the international distribution of technological competencies, and strengthen countries' and regions' technological competitiveness. Policy questions can be raised about the most effective means to attract the two types of R\&D. Moreover, technology management implications can be drawn about the change in the strategy, organisation and management of $R \& D$, especially in large multinational companies.

\section{Description of the data}

The 12th Jetro survey of Japanese manufacturing operations established in Europe (Jetro, 1996) lists 308 R\&D investments and 491 manufacturing affiliates. Jetro data on R\&D establishments in Europe are available from 1989, when Japan accounted for 149 R\&D facilities. Since then, the number of companies performing R\&D and the number of "stand-alone" R\&D labs have grown steadily. By the end of 1995 the UK, France and Germany accounted for almost $60 \%$ of the manufacturing activities and for about $70 \%$ of the R\&D bases $(65 \% \mathrm{R} \& \mathrm{D}$ facilities attached to manufacturing plants and $76 \%$ independent labs). ${ }^{5}$ We use the European addresses of the affiliates to describe their geographical distribution, and the information provided by the special section on R\&D operations to classify the investments as:

1. Affiliates belonging to a high-tech sector (235 investments in pharmaceuticals and electronics); to a medium-tech sector (470 affiliates in chemicals, electrical machinery, and motor vehicles); and to a low-tech sector (76 affiliates in food, drink and tobacco, and paper and printing). There are 18 missing observations because the Jetro survey does not specify the activity of the affiliate.

2. Affiliates performing only $R \& D$ independently of production (hereafter $\mathrm{R} \& \mathrm{D}$; they account for 72 affiliates), both $R \& D$ and production (hereafter R\&D-P; 236 affiliates), and production only (hereafter P; 491 affiliates). 
To describe the characteristics of the regions where the Japanese affiliates are located we use the REGIO and the European Patent Office data. The economic indicators are developed from the REGIO database (see Appendix I for details). Patent statistics - a proxy for the innovative activity in the areas -- are computed from the European Patent Office (EPO) during 1986-1990. Each patent is assigned to a specific region according to the address of the inventor. This is commonly thought as the actual location of the innovative activity. ${ }^{6}$ The geographical unit of analysis is the European region according to the NUTS classification (Nomenclature des Unités Territoriales Statistiques). This classification subdivides the European Union in 77 groups of regions (NUTS1), 206 regions (NUTS2) and 1031 provinces (NUTS3). One novelty of this paper is that it uses data at the most disaggregated NUTS3 level. ${ }^{7}$

Figure 1,2, and 3 in Appendix 2 show the geographical distribution of the three types of laboratories. There is a large difference in the number of regions hosting R\&D, R\&D-P, and P. Although all of them seem to cluster across European regions, R\&D-P and $\mathrm{P}$ tend to locate in a larger number of areas. Specifically, R\&D-P and P are located where $R \& D$ also is, in addition to a large number of other regions with no $R \& D$. In other words, there are no regions hosting only $R \& D$ labs, while there are several regions with only R\&D-P and $\mathrm{P}$. This is consistent with our idea that R\&D is concentrated in a few regions, and more applied activities are spread in many more contexts. In particular, the areas around London, Frankfurt and Paris host more than $30 \%$ of the R\&D affiliates. Differently, 7 and 8 regions - those around London, Frankfurt, Paris, Barcelona, Birmingham, Amsterdam, Munich, and Dublin -- account for $30 \%$ of R\&D-P and P respectively.

Table 1 looks at the sectoral characteristics of the affiliates. It computes the distribution of the three types of investments by sectoral class -- i.e. high-tech, medium-tech and low-tech sectors. The values in the cells are the joint frequencies that an affiliate in the jth sector (j=high-tech, medium-tech, low-tech) is of an ith type $(\mathrm{i}=\mathrm{R} \& \mathrm{D}, \mathrm{R} \& \mathrm{D}-\mathrm{P}, \mathrm{P})$. 
TAB. 1: Bivariate Distribution of R\&D, R\&D-P and P affiliates in Europe by sectoral classes.

\begin{tabular}{||c|c|c|c|c||}
\hline $\begin{array}{c}\text { Sectoral classes according } \\
\text { to their scientific content }\end{array}$ & $\begin{array}{c}\text { R\&D } \\
\text { Affiliates (\%) }\end{array}$ & $\begin{array}{c}\text { R\&D-P } \\
\text { affiliates (\%) }\end{array}$ & $\begin{array}{c}\text { P } \\
\text { affiliates (\%) }\end{array}$ & Total (\%) \\
\hline High-tech sectors & 5.5 & 9.6 & 15.3 & 30.4 \\
\hline Medium-tech sectors & 3.6 & 18.0 & 38.3 & 59.9 \\
\hline Low-tech sectors & 0.1 & 1.7 & 7.9 & 9.7 \\
\hline Total $(\%)$ & 9.2 & 29.3 & 61.5 & 100.0 \\
\hline
\end{tabular}

Source: Jetro

If we take the sectoral characteristics as a proxy for the science-content of the research performed, Table 1 can provide some indication about the scientific intensity of the three types of laboratories. The R\&D column shows that the higher the science content of a sector, the greater the probability that $R \& D$ is separated from production. By contrast, R\&D-P and P have a higher probability to belong to a medium-tech sector. The table also shows that the three types of investment are "sensitive" to changes in the technological class: R\&D moves from $5.5 \%$ in the high-tech class, to $3.6 \%$ and $0.1 \%$ in the medium and low-tech classes, respectively; R\&D-P goes from $9.6 \%$, to $18.0 \%$, and $1.7 \%$; P moves from $15.3 \%$, to $38.3 \%$, and $7.9 \%$.

The main result of this table is that it highlights the importance of $R \& D$ in high-tech businesses for the separation of research from production. In fact, the table shows that the linkage with production is always very important for carrying out $\mathrm{R} \& \mathrm{D}$, even in the high-tech sectors. ${ }^{8}$ However, in the high-tech sectors, this is comparatively less so. By comparing the R\&D and R\&D-P composition of the three sectoral classes in Table 1, it is apparent that the higher is the scientific content, the higher is the probability that research is performed independently of downstream production activity. Thirty-seven percent of the research in the high-tech sectors - i.e. $5.5 \% \mathrm{R} \& \mathrm{D}$ vs. $9.6 \% \mathrm{R} \& \mathrm{D}-\mathrm{P}$-- is independent of production. In the medium-tech sectors this share falls to $16.7 \%$-- i.e. $3.6 \% \mathrm{R} \& \mathrm{D}$ vs. $18.0 \% \mathrm{R} \& \mathrm{D}-\mathrm{P}$-- and to $5.6 \%$ in the low-tech sectors - i.e. $0.1 \%$ R\&D and 1.7\% R\&D-P. This is consistent with the idea of science-intensive research being more separable from production. This is also consistent with other empirical studies. For example, Florida and Kenney (1994) point out that the majority of R\&D investments operated by Japanese companies abroad are applied and product development research which is located close to existing manufacturing sites. A smaller number of investments in more science-based sectors 
are near major universities and scientific research centres to gain access to the sources of new knowledge.

Moreover, some preliminary observations about the location patterns arise from the distribution of the economic and innovative indicators in the regions with R\&D, R\&D-P and P investments. We compare the means of the following variables: population (POP), population density (DEN), Gross Domestic Product (GDP), GDP per capita (GDPPC), the share of the employees in the service sector over the total number of employees (EMP3), the share of employees in industry over the total number of employees (EMP2), the number of patents in the area (PAT), and the number of regional patents belonging to the sector in which the affiliate is active (PATSEC). Table 2 shows the average characteristics of the regions that host the three types of affiliates. The results for EMP3 and EMP2 are not shown because there is not significant variation across the three choices.

TAB. 2: Means of regional indicators by $R \& D, R \& D-P$ and $P$ affiliates.

\begin{tabular}{|c|c|c|c|c|c|c|}
\hline $\begin{array}{l}\text { Type of } \\
\text { affiliate }\end{array}$ & $\begin{array}{c}\text { Mean of } \\
\text { PAT }\end{array}$ & $\begin{array}{l}\text { Mean of } \\
\text { PATSEC }\end{array}$ & $\begin{array}{l}\text { Mean of } \\
\text { GDPPC }\end{array}$ & $\begin{array}{l}\text { Mean of GDP } \\
\text { (millions of } \\
\text { ECU's) }\end{array}$ & $\begin{array}{l}\text { Mean of } \\
\text { POP } \\
\text { (thousands) }\end{array}$ & $\begin{array}{l}\text { Mean of } \\
\text { DEN } \\
(\mathrm{x} \mathrm{km} 2)\end{array}$ \\
\hline$R \& D$ affiliates & $\begin{array}{l}150.0 \\
(18.50)\end{array}$ & $\begin{array}{l}13.3 \\
(2.33) \\
\end{array}$ & $\begin{array}{c}22875.4 \\
(1143.2) \\
\end{array}$ & $\begin{array}{c}33 \\
(3.8) \\
\end{array}$ & $\begin{array}{l}1885.7 \\
(216.5)\end{array}$ & $\begin{array}{c}3089.4 \\
(500.4) \\
\end{array}$ \\
\hline$R \& D-P$ affiliates & $\begin{array}{l}88.7 \\
(9.77) \\
\end{array}$ & $\begin{array}{c}6.52 \\
(1.24) \\
\end{array}$ & $\begin{array}{c}16932.0 \\
(615.9)\end{array}$ & $\begin{array}{c}19 \\
(2.1)\end{array}$ & $\begin{array}{l}1356.4 \\
(115.7) \\
\end{array}$ & $\begin{array}{c}1418.2 \\
(268.8)\end{array}$ \\
\hline$P$ affiliates & $\begin{array}{r}92.6 \\
(7.19) \\
\end{array}$ & $\begin{array}{c}8.1 \\
(0.91) \\
\end{array}$ & $\begin{array}{c}16457.4 \\
(468.1) \\
\end{array}$ & $\begin{array}{c}14 \\
(1.4) \\
\end{array}$ & $\begin{array}{c}1185.4 \\
(83.6)\end{array}$ & $\begin{array}{c}1461.6 \\
(193.2) \\
\end{array}$ \\
\hline
\end{tabular}

Source: Jetro, Elaboration from the EPO data, and EUROSTAT

Note: Standard errors in parentheses.

As one would expect the mean of patents - both total patents and sectoral patents -- is higher for $R \& D$ than for R\&D-P and P. It moves from an average of 150 patents invented in the regions with $\mathrm{R} \& \mathrm{D}$, to 88.7 and 92.6 patents in the regions with R\&D-P and P respectively. Similarly, when one considers only the mean of patents invented in the sector of the affiliate's activity, it goes from 13.3, to 6.52, and 8.1 in the regions with $R \& D, R \& D-P$ and $P$ respectively. Hence, $R \& D$ is more probably located in the areas with a higher technological standard -- almost twice as much as the others. This is suggestive of the importance of the technological external economies and knowledge spillovers for establishing independent R\&D labs. 
Similar results are obtained with the mean of GDPPC and GDP. Both of them are considerably higher in the regions with R\&D affiliates. The mean of GDPPC moves from 22,875 ECU per capita in the regions with R\&D, to 16,932 ECU, and $16,457 \mathrm{ECU}$ in the areas with R\&D-P and P. The figures for the total GDP are even more apparent. The average is 33 millions ECU in the regions with R\&D. This average falls to 19 millions ECU in the regions that host R\&D-P, and to 14 millions ECU in the case of P. Furthermore, not only are the regions hosting independent R\&D labs richer, but on average, they are also more populated and the population is more concentrated, as shown by the last two columns of Table 2 .

\section{The econometric specification}

Table 1 and 2 describe the average characteristics of the areas where R\&D, R\&D-P and $\mathrm{P}$ are located. Although interesting, however, they do not take into account multiple correlations. To do so the paper proceeds with the estimates of a multinomial logit model, which explains what factors influence the relative probability that a Japanese company sets up an independent R\&D lab (R\&D), an R\&D lab attached to a production facility $(\mathrm{R} \& \mathrm{D}-\mathrm{P})$, or a production plant $(\mathrm{P})$.

The model is specified as follows. The total sample is composed of 539 Japanese investments in Europe $(i=1, \ldots . ., 539) .{ }^{9}$ The choices are coded as $\mathrm{j}=0,1,2$-$P, R \& D-P$, and $R \& D$ respectively. Let $V_{i}^{j}$ be the benefits accruing if the investment $j$ is chosen. $\mathrm{V}_{\mathrm{i}}^{\mathrm{j}}$ will depend on the characteristics of both the choice and the individuals making the choice. The multinomial choice models can be motivated by assuming that individuals maximise utility, and that utility that derives from the choice of the jth alternative is a function of a vector of variables representing the attributes of the $j$ th choice to the ith individual. This paper uses data that varies across individuals, but not across alternatives. Such data includes:

1. PATSEC - i.e. the technological activity in the region, in the affiliate's sector. This is proxied by the number of patents belonging to the affiliate's industry and invented in the area where the Japanese investment is located. We expect that stand-alone laboratories are attracted by a technologically conducive external environment more than production related activities. This would be consistent also 
with Table 1 that shows that stand-alone laboratories have the highest probability to belong to a science intensive sector. Science intensive activities should benefit more than low-tech activities from knowledge spillovers and technological external economies. Hence, we expect a positive impact of PATSEC on the likelihood of an investment being an R\&D type $\left(\beta^{R \& D}>0\right.$ and $\left.\beta^{R \& D}>\beta^{R \& D-P}\right) .^{10}$

2. GDPPC - i.e. the per capita Gross Domestic Product. This is suggestive of the extent of richness and economic development of the regions. We expect a positive effect of GDPPC on both R\&D-P and R\&D, compared to only P. Being the latter more sensitive to the availability of low wage workers, it should be comparatively less attracted to high GDPPC areas.

3. SEMP3 - i.e. the share of employees in the service sector over the employees in the industry sector. The availability of transport, communication, finance, banking, and insurance services is used as a raw measure of the local infrastructures. We expect a positive sign of the R\&D and R\&D-P coefficients with respect to only $P$.

4. POP - i.e. the population, used as a control variable for the size of the region. We expect that the size of the region does not affect the establishment of R\&D either with or without production more than it does with production only.

5. DEN - i.e. the population density. This is a proxy for the congestion and external diseconomies in the regions. This variable should have a negative impact on both $R \& D$ and R\&D-P. By contrast, in the case of $\mathrm{P}$, part of the congestion might be compensated by the larger and more concentrated demand.

Hence:

$$
\begin{aligned}
& V_{i}{ }^{j}=\beta_{0}{ }^{j}+\beta_{1}{ }^{j} \cdot P_{A T S E C}+\beta_{2}{ }^{j} \cdot \text { GDPPC }_{i}+\beta_{3}{ }^{j} \cdot \text { SEMP }_{i}+\beta_{4}{ }^{j} \cdot P P_{i}+\beta_{5}{ }^{j} \cdot \text { DEN }_{i}+u_{i}{ }^{j} \\
& j=0,1,2,
\end{aligned}
$$

with $u_{i}^{j}(j=0,1,2)$ being the error terms. Let then $d_{i}^{j}(j=0,1,2)$ be a random variable that equals 1 if alternative $\mathrm{j}$ is chosen and 0 if it is not. It results:

$$
\mathrm{d}_{\mathrm{i}}^{\mathrm{j}}=1 \text { if } \mathrm{V}_{\mathrm{i}}^{\mathrm{j}}>\mathrm{V}_{\mathrm{i}}^{\mathrm{k}}, \forall \mathrm{k} \neq \mathrm{j} \text {; otherwise } \mathrm{d}_{\mathrm{i}}^{\mathrm{j}}=0, \quad \mathrm{j}=0,1,2 \text {. }
$$


In this formulation, in order for the model to be identified, the coefficients of one of the alternatives have to be set to 0 . We set $\beta_{\mathrm{k}}{ }^{0}=0, \mathrm{k}=1, \ldots ., 5$. In other words, the $\mathrm{P}$ category is taken as the baseline in the econometric estimates.

\section{The empirical findings}

Our empirical analysis does not test a structural model. It is rather a means to describe some general trends in the location of $\mathrm{R} \& \mathrm{D}$. The results of the econometric estimates are shown in Table 3.

TAB. 3: Estimates of the multinomial logit model

\begin{tabular}{|c|c|c|c|}
\hline & & $\mathrm{R} \& \mathrm{D}-\mathrm{P}\left(\beta_{\mathrm{k}}^{\mathrm{R} \& \mathrm{D}-\mathrm{P}}\right)$ & $\mathrm{R} \& \mathrm{D}\left(\beta_{\mathrm{k}}^{\mathrm{R} \& \mathrm{D}}\right)$ \\
\hline$\beta_{0}$ & Constant & $\begin{array}{c}-9.23 \\
(3.927)\end{array}$ & $\begin{array}{l}-23.571 \\
(5.389)\end{array}$ \\
\hline$\beta_{1}$ & PATSEC & $\begin{array}{c}-0.10 \\
(0.110) \\
\end{array}$ & $\begin{array}{c}0.343 \\
(0.164) \\
\end{array}$ \\
\hline$\beta_{2}$ & GDPPC & $\begin{array}{c}0.82 \\
(0.394)\end{array}$ & $\begin{array}{c}2.14 \\
(0.530)\end{array}$ \\
\hline$\beta_{3}$ & SEMP3 & $\begin{array}{c}-0.34 \\
(0.108) \\
\end{array}$ & $\begin{array}{c}0.425 \\
(0.144) \\
\end{array}$ \\
\hline$\beta_{4}$ & POP & $\begin{array}{c}0.16 \\
(0.110) \\
\end{array}$ & $\begin{array}{l}-0.045 \\
(0.193) \\
\end{array}$ \\
\hline$\beta_{5}$ & DEN & $\begin{array}{l}-0.0607 \\
(0.0407) \\
\end{array}$ & $\begin{array}{c}-0.161 \\
(0.0476) \\
\end{array}$ \\
\hline \multicolumn{2}{|c|}{ N. of $P$ choices } & \multicolumn{2}{|c|}{$307(0.57 \%)$} \\
\hline \multicolumn{2}{|c|}{ N. of R\&D-P choices } & \multicolumn{2}{|c|}{$178(0.33 \%)$} \\
\hline \multicolumn{2}{|c|}{ N. of R\&D choices } & \multicolumn{2}{|c|}{$54(0.10 \%)$} \\
\hline \multicolumn{2}{|c|}{ Number of observations } & \multicolumn{2}{|c|}{539} \\
\hline \multicolumn{2}{|c|}{ Log-likelihood } & \multicolumn{2}{|c|}{-470.400} \\
\hline
\end{tabular}

Source: Jetro, Elaboration from the EPO data, and EUROSTAT Note: Standard errors in parentheses.

The coefficient $\beta_{1}$ refers to the technological environment in which research is performed. It is negative but not significant for R\&D-P. It is positive and significant in the case of R\&D. Hence: $\beta_{1}{ }^{R \& D-P}=\beta_{1}{ }^{P}$ and $\beta_{1}{ }^{R \& D}>\beta_{1}{ }^{P}\left(\right.$ and,$\left.\beta_{1}{ }^{R \& D}>\beta_{1}{ }^{R \& D-P}\right)$, meaning that PATSEC influences the location of R\&D more than R\&D-P and P. The better is the technological environment, the greater is the probability of having $R \& D$ independently of production activity. By contrast, the availability of technological factors do not play any role in attracting $R \& D$ attached to production compared to only production affiliates. This means that changes in the technological characteristics 
do not affect the probability of setting up R\&D-P affiliates compared to only $\mathrm{P}$ facilities.

By contrast, the GDPPC is positively correlated with both R\&D-P and R\&D, influencing both the location of $R \& D$ and $R \& D-P$ compared to $P$ only. Precisely: $\beta_{2}{ }^{\mathrm{R} \& D-P}>\beta_{2}{ }^{\mathrm{P}}$ and $\beta_{2}{ }^{\mathrm{R} \& D}>\beta_{2}{ }^{\mathrm{P}}$ (and $\beta_{2}{ }^{\mathrm{R} \& D}>\beta_{2}{ }^{\mathrm{R} \& D-P}$ ), and both coefficients are significant. The greater coefficient for $R \& D$ shows that $R \& D$ independent labs are more sensitive to the attractiveness of richer regions compared to R\&D-P. These regions are probably also the most technologically advanced.

The regressions suggest that the likelihood of independent R\&D located in a region increases with the service-intensity of the area. The coefficient of SEMP3 is positive and significant in the $R \& D$ estimates. It is negative and significant in the R\&D-P estimates: $\beta_{3}{ }^{R \& D-P}<\beta_{3}{ }^{P}$ and $\beta_{3}{ }^{R \& D}>\beta_{3}{ }^{P}$. Hence, when the share of services increases with respect to the industry, the probability of setting up R\&D-P falls with respect to $\mathrm{P}$. This is also because $\mathrm{R} \& \mathrm{D}-\mathrm{P}$ is positively influenced by the presence of production and industrial activities. By contrast, the higher the share of the service sector over the industry, the greater the probability that $R \& D$ localises in the area compared to $\mathrm{P}$ and R\&D-P.

The population (POP) is a control variable for the size of the regions. It has a positive though not highly significant coefficient in the R\&D-P estimate. The coefficient of R\&D takes the wrong sign, but is not significant. By contrast, the density of the population (DEN) takes a negative coefficient in both estimates, but it is more significant in the R\&D than in the R\&D-P estimate. These findings support the idea that, due to the congestion problems that might arise in highly concentrated and populated areas, there is a limit to the agglomeration. Above a certain threshold, the geographical concentration might cause problems that make the probability of $R \& D$ and R\&D-P fall. Furthermore, such diseconomies produce a greater effect on R\&D than on R\&D-P.

As noticed in the set up of the model, the multinomial logit regression produces only indications about $R \& D$ and $R \& D-P$ relatively to the baseline case $\mathrm{P}$. To show the 
order of magnitude of the empirical relationships so highlighted we use two simulation exercises. The first exercise is based on the estimated parameters. It looks at the "substitution ratio" between different local factors in order to maintain the "value" of the region unchanged for the location of $R \& D$. The coefficients of the estimates show that higher PATSEC, GDPPC and SEMP3, and lower DEN increase the probability to have $R \& D$ compared to R\&D-P and P. Then the question is: how much should one of these factor increase or decrease to compensate for a change in another factor? If for example GDPPC decreases by 10\%, how many more "sectoral" patents (PATSEC) should a region have to maintain the same probability of $R \& D$ ? By substituting the estimated parameters in the expression $\left(-\beta_{1}{ }^{\mathrm{R} \& \mathrm{D}} / \beta_{2}{ }^{\mathrm{R} \& \mathrm{D}}\right) *(-10 \%)$ we derive that PATSEC should increase by $1.6 \%$ to maintain the same level of attractiveness of the regions. The exercise can be repeated for all the combinations of regional factors and their changes. Far from being a way to establish rigorous rules for substituting among different local factors, the purpose of this exercise is to produce some indication about the local factors that can improve the attractiveness of the regions, given their initial conditions.

The second exercise uses the estimated changes in probabilities shown in Table 4. These are computed as the marginal effects of changes in the independent variables over the probabilities to observe P, R\&D-P, and R\&D in the regions - i.e. the "shares" of $\mathrm{P}, \mathrm{R} \& \mathrm{D}-\mathrm{P}$, and $\mathrm{R} \& \mathrm{D}$ in a region with given characteristics.

TAB. 4: Changes in probabilities of $P, R \& D-P$ and $R \& D$ due to changes in the explanatory variables

\begin{tabular}{||c|c|c|c||}
\hline \hline $\mathrm{X}$ & $\mathrm{dP}(\mathrm{P}) / \mathrm{dX}$ & $\mathrm{dP}(\mathrm{R} \& \mathrm{D}-\mathrm{P}) / \mathrm{dX}$ & $\mathrm{dP}(\mathrm{R} \& \mathrm{D}) / \mathrm{dX}$ \\
\hline PATSEC & 0.002 & -0.033 & 0.031 \\
\hline GDPPC & -0.262 & 0.11 & 0.148 \\
\hline SEMP3 & -0.014 & -0.021 & 0.035 \\
\hline POP & -0.027 & 0.036 & -0.009 \\
\hline DEN & 0.019 & -0.008 & -0.011 \\
\hline
\end{tabular}

Source: Jetro, Elaboration from the EPO data, and EUROSTAT

The exercise shows: (1) the change in the explanatory variables needed to increase by a certain amount the share of $R \& D$ investment in a region; (2) the effect that the change in the explanatory variable produces over the probability of R\&D-P and $\mathrm{P} .{ }^{11}$ Suppose that our goal is to increase by $0.01(1 \%)$ the share of R\&D 
investments in the area. Then, how much should the explanatory variables increase/decrease to achieve this goal?

Just to give some examples, PATSEC should increase by $30 \%$. This change, in turn, would lead R\&D-P to decrease by $1 \%$. P would remain constant. ${ }^{12}$ Hence, the positive effect on $R \& D$ is totally compensated by the negative impact on R\&D-P. This implies that more sectoral patents in a region have a zero net effect on the location of research. It only changes the composition of research performed in the area. The case of GDPPC is different. By augmenting the GDPPC, the positive effect on R\&D and R\&D-P is entirely compensated by a reduction in the share of $\mathrm{P}$ investments. The net effect on the probability to attract research is positive, and the composition of the research performed changes slightly in favour of $\mathrm{R} \& \mathrm{D}$. Again, we do not perform all the possible changes in the local factors and their effects. The aim of this example is to suggest that there are different local factors that one can foster in order to attract the location of $R \& D$ in a region. The choice among them depends upon the type of research that one wants to attract, and on the initial conditions of the regions - i.e. already existing laboratories and factors endowment. Moreover, the effect of an initial change can produce effects (negative or synergetic) on all the types of investments.

\section{Discussion: Managerial and policy implications}

The upsurge of important technological advances, new computational capabilities, and scientific discoveries create new opportunities for the production of knowledge. In turn, they allow for a new organisation of research activities at three levels: among different economic agents, within the firm - especially large multinational enterprises - and geographically. In so doing, they open up new approaches to the management of $\mathrm{R} \& \mathrm{D}$, and raise relevant policy issues. We will discuss both of them in the reminder of this section.

As far as the management of $R \& D$ is concerned, many recent contributions to the study of the international management focus on the so-called "network corporation". ${ }^{13}$ They represent the "network corporation" as the firm that has 
abandoned the traditional view of the company organised hierarchically, through rigid biunivocal relationships between the headquarter and the subsidiaries. The company is increasingly becoming a world-wide network, whose different units are potential sources of ideas, skills and knowledge that can be harnessed from the environment in which they are located. This is particularly relevant when the firm's units are R\&Doriented, and when the company has the capability to organise and transmit the results achieved in one point of the network to the whole organisation.

Our results suggest that companies that belong to a high-tech sector can better manage their R\&D activities through this network approach. It seems, indeed, that when some scientific work is performed, firms have a higher opportunities to separate the research tasks, to "modularise" the R\&D activities, and to locate them in different places, according to the most suitable technological environment for each task. In so doing they can reap greater economies internal and external to the firm. They can concentrate the production of generic research (because of its implicit transferability) in a few units, and in few selected geographical areas. Contextual research can use the upstream modules produced under more efficient conditions for specific applications. By avoiding the costly duplication of the investment in generic research, this would maximise the economies internal to the firm. By locating the research tasks in the most conducive places, firms can also benefit from "task-specific" external economies.

Clearly, this new organisation of R\&D has implications for the structural properties of the large and typically diversified network-firm. Geographical and organisational decentralisation of R\&D asks for co-ordination, communication, and control capabilities in order to ensure the efficiency and effectiveness of research activities. The capability to transfer the know-how accessed world-wide, and to combine different pieces of knowledge become strategic for developing innovations. By implication, the simpler is the product-system, and the organisational internal ties, the easier is the knowledge transfer and assembling. By contrast, the more numerous and complex are the interdependencies among the different organisation's groups and product's parts, the more difficult and costly is the decomposition and the subsequent integration of the sub-tasks. 
This complexity might require the creation of a function/manager within the firm -- the "system-integrator" - who partitions the knowledge production process in such a way to reduce the complexity of the system and minimise the interdependencies among the sub-tasks (von Hippel, 1990 and 1994). To do so the "system-integrator" must know how the whole system works, and how the single pieces -- people and knowledge -- are interconnected. This makes it possible to effectively sub-divide the system in different self-contained modules. Clearly, the strategic management of technology requires new combinations of skills and expertise that are difficult to forge. Good managers of a network-corporation should know both about marketing, finance, and production fields - as the traditional entrepreneur does - and about $R \& D$, with the long-term vision that $R \& D$ projects require. ${ }^{14}$

Our analysis raises also a number of policy questions. One of the major concerns in Europe is its technological competitiveness with respect to the US and Japan. A way to improve competitiveness is by fostering scientific and technological progress. The attraction of $R \& D$ activities becomes then crucial. The question is how to attract R\&D? Even though policy measures aimed at promoting R\&D investments cannot be tailored with extreme precision, our results suggest that, policy makers who want to foster the R\&D activities in a certain country/region, can develop different strategies, depending upon the targeted type of R\&D.

Normally, corporate investment decision is made considering not only R\&D and technology, but also other factors such as marketing and production. However, also the establishment of marketing and production activities give rise to $R \& D$. Hence, measures that attract industrial and production activities can increase the probability that some $\mathrm{R} \& \mathrm{D}$ is performed - probably contextual research, as our results suggest. By contrast, a technologically rich environment seems to better attract scientific research. Hence, measures that foster technology-related factors and other agglomeration economies increase the probability of science-intensive R\&D performed by independent labs. This distinction helps simplify the complex problem of how different location factors influence the setting up of laboratories linked or independent of production. In fact, the trade-off between one source of advantage and 
another is usually very blurred, mixed, and more often what matters for the investors is how different factors correlate with one another. Prospective companies can even negotiate with government special local conditions, and eventually buy "a package" of different local amenities.

However, our simplified framework shows that local factors that attract one type of research might produce negative or synergetic effects on the location of the other type of $\mathrm{R} \& \mathrm{D}$, depending upon the initial conditions of the regions. Moreover, since there is considerable variation in the contingent characteristics of different countries and regions, a poorly endowed region from the technological point of view might better succeed in fostering production than patenting activity. If anything, this also suggests that strategies based on the superimposition of Science and Technology Parks in less developed regions might be less appealing than strategies based on encouraging foreign production operations, which may then in turn carry $R \& D$ operations with them.

\section{Concluding remarks}

By means of regional data on European economic and innovative characteristics and Japanese investments, this paper tried to shed some light on the location pattern of R\&D. The aim of the paper was twofold. First, it looked at whether the scientific content of R\&D influences the possibility to separate R\&D from production. Second, by means of a multinomial logit model, it described the regional factors needed to attract $R \& D$ not linked to production activities.

To address the first of these issues, we compared the average scientific content of R\&D and R\&D-P activities. Our analysis confirms the idea that research, even science-intensive research, typically follows the establishment of production. There are 178 R\&D-P - i.e. joint production and R\&D -- against 54 R\&D affiliates. However, as the science-intensity increases, the linkage with production is relatively less important. The higher probability of separating research from production in science-intensive sectors helps improve the trade-off in the localisation of research. More scientific work can be centrally performed in the areas with technological external economies, and far 
from downstream production activities. Knowledge, once produced, can be used in different contexts by investing only in the complementary contextual research and production activities. The possibility to avoid the duplication of costly R\&D encourages its exploitation in a larger number of contexts, even in more marginal ones. Here, the knowledge generated in the "core" regions can be used at the marginal cost by investing only in the local development of more downstream research and production activities.

Moreover, the results of the multinomial logit regression suggest that while $\mathrm{R} \& \mathrm{D}-\mathrm{P}$ is attracted to the same factors that influence $\mathrm{P}, \mathrm{R} \& \mathrm{D}$ is localised according to different local characteristics - i.e. "agglomeration economies". The probability of an affiliate being an independent R\&D lab clearly increases with the technological characteristic of the region, the richness of its population, the share of services produced compared to the industrial output, and decreases with the density of the population. Specifically, an increase in PATSEC - i.e. the number of sectoral patents invented in the region -- produces a sharp increase in the probability of an investment being $R \& D$ compared to $P$, while it has no impact on R\&D-P. In other words, the location of R\&D-P appears totally independent of the technological environment of the region. Similarly, when SEMP3 increases -i.e. the share of employees in the service sector over the employees in the industry - the probability of a lab being R\&D increases as well, while the probability of a lab being R\&D-P falls. This also suggests that R\&D-P is positively influenced by the presence of industrial activities.

Acknowledgements: I would like to thank Alfonso Gambardella, John Hagedoorn, Rajneesh Narula, Keith Pavitt, Ed Steinmueller, and Nick von Tunzelman for constructive comments and suggestions. I am also indebted to Marjolein Caniels for giving me access to the regional databases, and to Hugo Hollanders for solving my numerous computer problems in dealing with data. I take full responsibility for the contents of this paper. 


\section{Appendix I}

TAB. I: The explanatory variables

\begin{tabular}{||c|l||}
\hline Variable & \multicolumn{1}{c|}{ Definition } \\
\hline PATSEC & $\begin{array}{l}\text { Number of "sectoral" patents - i.e. patents issued in the sector in } \\
\text { which the affiliate is active. This number is computed as the mean } \\
\text { of patents invented every year (1986-1990) in each region }\end{array}$ \\
\hline PAT & Average number of patents invented in each region in 1986-1990 \\
\hline GDPPC & $\begin{array}{l}\text { Per capita Gross Domestic Product calculated as the average GDP } \\
\text { per capita in 1988-1992, and adjusted for the Purchasing Power } \\
\text { Parity with the ECU. }\end{array}$ \\
\hline $\begin{array}{c}\text { GDP } \\
\text { (millions of ECU's) }\end{array}$ & $\begin{array}{l}\text { Average Gross Domestic Product in 1988-1992, adjusted for the } \\
\text { Purchasing Power Parity with the ECU. }\end{array}$ \\
\hline SEMP3 & $\begin{array}{l}\text { Share of employees in the service sector over the employees in the } \\
\text { industry sector. It is calculated as the average share in 1984-1988 }\end{array}$ \\
\hline EMP2 & $\begin{array}{l}\text { Share of employees in the industry sector over total employees. It is } \\
\text { calculated as the average share in the years 1984-1988 }\end{array}$ \\
\hline EMP3 & $\begin{array}{l}\text { Share of employees in the service sector over total employees. It is } \\
\text { calculated as the average share in the years 1984-1988 }\end{array}$ \\
\hline $\begin{array}{c}\text { POP } \\
\text { (thousands) }\end{array}$ & Average population in 1988-1992 \\
\hline $\begin{array}{c}\text { DEN } \\
\text { (x km2) }\end{array}$ & Thousands of people for squared Km. Average in 1988-1992. \\
\hline
\end{tabular}

Source: Jetro, Elaboration from the EPO data, and EUROSTAT

Note: all the explanatory variables are collected at the NUTS3 level. 


\section{Appendix 2}

Fig. 1: The Geographical distribution of $R \& D$ affiliates

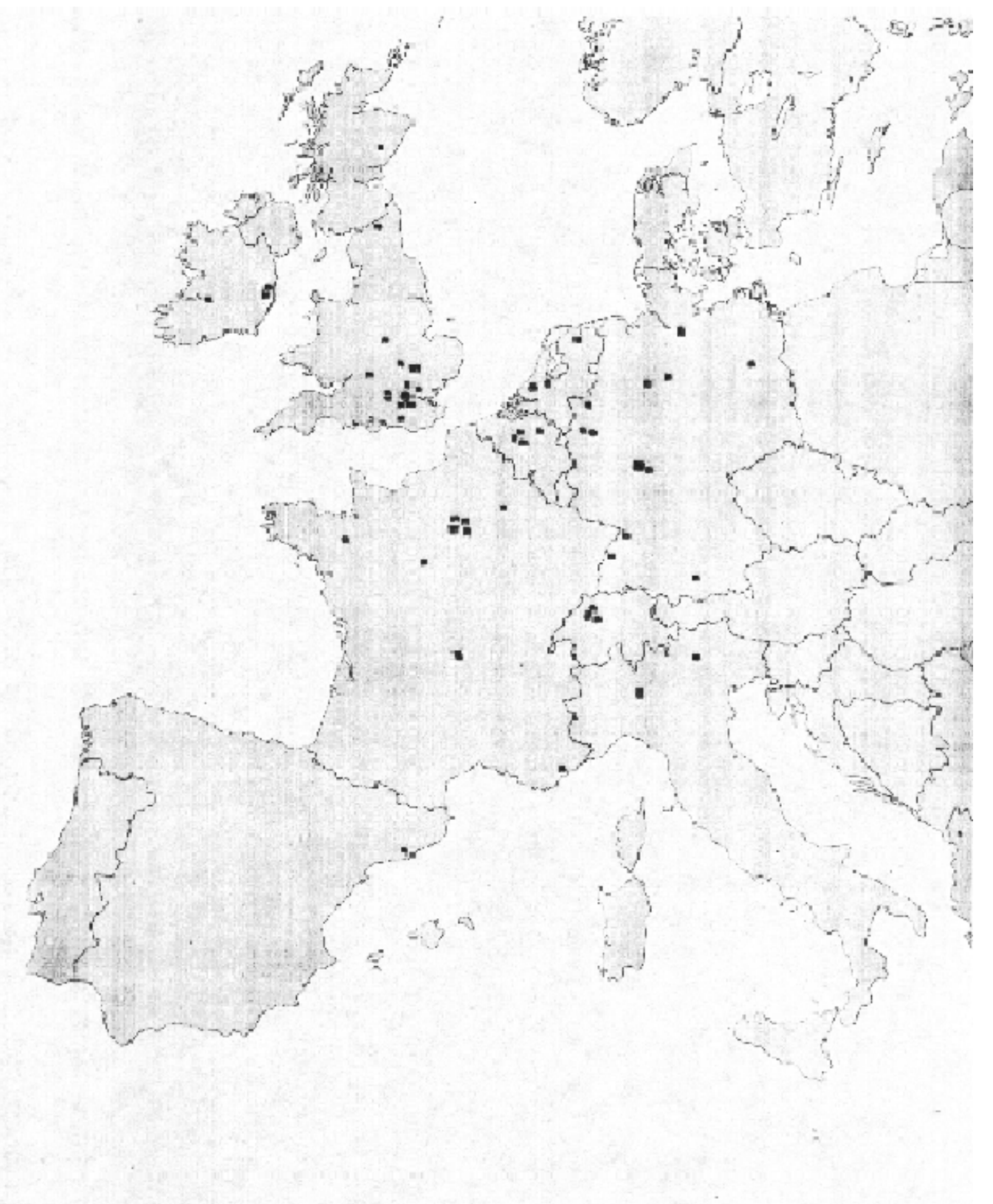


Fig. 2: The Geographical distribution of R\&D-P affiliates

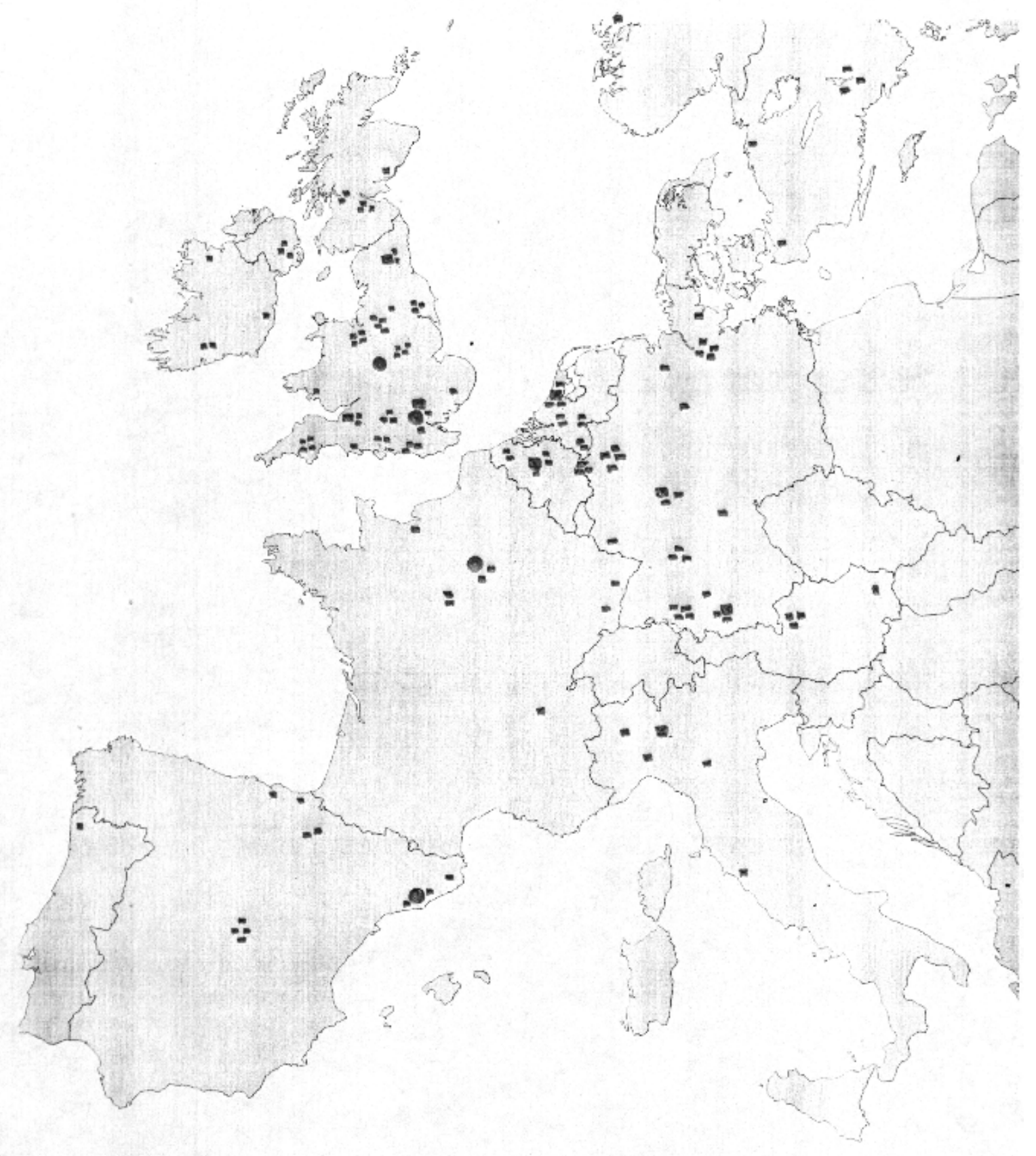


Fig. 3: The Geographical distribution of $P$ affiliates

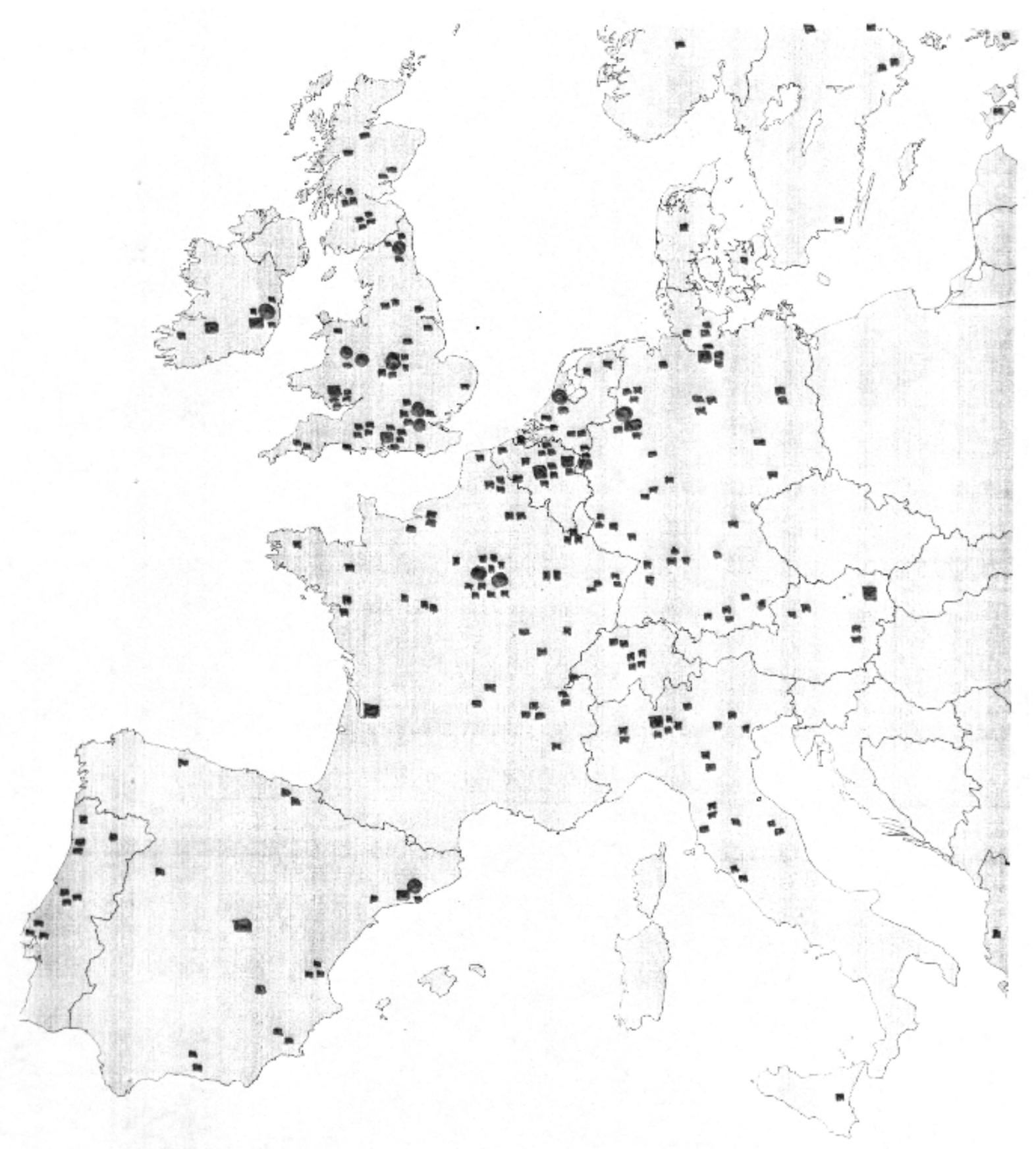




\section{Bibliography}

Archibugi D., Michie J., 1995 "The globalisation of technology : a new taxonomy" Cambridge Journal of Economics

Archibugi D., Pianta M., 1992, The technological specialisation of Advanced countries. A report to the EEC on international science and technological activities.

Arora A., Gambardella A.,1994 "The changing technology of technological change: general and abstract knowledge and the division of labour", Research Policy

Audretsch D.B and Feldman M., 1996 "R\&D spillovers and the geography of innovation and production", The American Economic Review

Bartlett C.A., 1986 "Building and Managing the Transnational: The New Organizational Challange" in M.E. Porter (ed.), Competition in Global Industries 367401, Boston, Harward Business School Press, Boston, MA

Bartlett C.A. and Goshal S. 1989, Managing across borders, Harward Business School Press, Boston, MA

Bartlett C.A. and Goshal S., 1990 "Managing Innovation in the Transnational Corporation" in C.A. Bartlett, Doz Y. and Hedlund G. (ed.) Managing the Global Firm, Routledge, London (pp. 215-255)

Bresnahan, T. and Trajtenberg M.,1995 "General purpose technologies: engines of growth?" Journal of Econometrics, vol65 (1), pp 83-108

Breschi S., 1995 "Spatial Patterns of Innovation: evidence from patent data" Paper presented at the workshop on New Research Findings: The Economic of Scientific and Technological Research in Europe, Urbino, Italy, 24-25

Caniels Marjolein, 1997 “The Geographic Distribution of Patents and Value Added Across European Regions" prepared for the 37th European Congress of the Regional Science Association, Rome, Italy, 26-29

Cantwell J., 1994, The globalisation of technology: what remain of the product cycle model?, Discussion Paper n. 185, University of Reading

Cantwell J., 1991 "The international agglomeration of R\&D" in Global Research Strategy and International Competitiveness, Casson M. (ed)

Casson M., Pearce R.D. and Singh S. 1992 "Business culture and International Technology" in Technology Management and International Business. Internationalisation of $R \& D$ and Technology, Granstrand, Hakanson and Sjolander (ed.) 
De Solla Price D., 1984 “The Science/Technology Relationship, the Craft of Experimental Science and Policy for the Improvement of High Technology Innovation" Research Policy, Vol.13 (1), pp.3-20

Duysters, G, Hagedoorn J., 1993 Internationalisation of corporate technology: an empirical investigation, MERIT Working Paper

Florida R., 1997 "The Globalisation of R\&D: Results of a survey of foreign-affiliated R\&D laboratories in the USA" Research Policy (26, 85-103)

Florida R., M. Kenney, 1994 “The organisation and geography of Japanese R\&D: results from a survey of Japanese electronics and biotechnology firms", Research Policy, $(23,305-323)$

Freeman C. and Hagedoorn J., 1992, Globalisation of Technology, MERIT Working Paper

Gerybadze A. and Reger G., 1997, Globalisation of R\&D: recent Changes in the Management of Innovation in Transnational Corporation, Discussion Paper on International Management and Innovation

Griliches Z., 1990 "Patent statistics as economic indicators: a survey” Journal of Economic Literature

Hedlund G., 1986 “The Hypermodern MNC - A Heterarcy?” Human Resource Management, 25, 9-35

Howells J., 1990 "The location and organisation of research and development: new horizons" Research Policy

Jaffe A.B., 1989 "Real effects of academic research", American Economic Review, 79: 957-70

Jaffe A.B., Henderson R. and Trajtenberg M., 1993 "Geographic localisation of knowledge spillovers as evidenced by patents citations" Quarterly Journal of Economics

Japaninfo, 1997, Directory of Japanese Addresses in Europe

JETRO, 1996, The 12th Survey of European Operations of Japanese Companies in the Manufacturing Sector

Krugman P., 1991, Geography and trade, Cambridge, MA: MIT Press

Lamoreaux N.R. and Sokoloff K.L., 1997, Location and technological change in the American glass industry during the late nineteenth and early twentieth centuries NBER Working Paper No. 5938

Marshall, 1920, Principles of Economics, Macmillan 
Patel P., 1993, Localised production of technology for global markets, SPRU Working Paper

Patel P., Pavitt K., 1992 "Large firms in the production of the world's technology: an important case of non-globalisation" in Technology management and International Business: Internationalisation of $R \& D$ and technology Granstrand O., Hakanson L. and Sjolander S. (ed) Wiley, New York.

Pearce R.D. and Singh S., 1992 "Internationalisation of Research and Development among the world's leading enterprises: survey analysis of organisation and motivation" in Technology management and International Business: Internationalisation of $R \& D$ and technology, Granstrand O., Hakanson L. and Sjolander S. (ed) Wiley, New York.

Scherer F.M., 1983 “The propensity to patent” International Journal of Industrial Organisation

Soete L., 1989, "The impact of technological innovation on international trade patterns: the evidence reconsidered", Research Policy, 16

von Hippel E., 1990 "task partitioning: and innovation process variable", Research Policy 19, 407-418

von Hippel E., 1994, “'Sticky information’ and the locus of problem solving: implications for innovation", Management Science, vol. 40 429-439

NOTES

${ }^{1}$ On "national specialization": Archibugi and Pianta 1992; Soete, 1989. On “clustering”: Marshall, 1920; Krugman, 1991; Cantwell, 1991.

2 See also: Archibugi and Michie, 1993; Duysters and Hagedoorn, 1993; Freeman and Hagedoorn, 1992; Howells, 1990; Patel, 1993; Pearce and Singh, 1992.

${ }^{3}$ See for example, Archibugi and Michie, 1995. Moreover, Audretsch and Feldman (1994) focus on the degree to which innovative activity clusters spatially. They find that the propensity for innovative activity to cluster is greater in industries where the creation of new knowledge and knowledge spillovers play a more important role.

${ }^{4}$ We do not exclude the possibility that the most technologically active regions are also attractive markets, so that some contextual and generic research activities are performed in the same regions. What matters, however, is that the former is less concentrated and located also in areas with no scientific research.

${ }^{5}$ Overseas R\&D activities by Japanese MNEs are still a limited phenomenon. Patel (1993) analysed the most internationalised firms among those with more than 20 patents granted in 1985-90. He pointed out that Japanese firms performed only $1 \%$ of technological activities abroad. Interestingly, however, besides the understanding that decentralised R\&D supports the adaptation of products to local market requirements, the Jetro survey confirms that such overseas labs develop new technological assets for long-term pre-competitive research.

${ }^{6}$ See Griliches (1990) and Scherer (1983) for the use of patents as a proxy for innovative activity.

${ }^{7}$ This is one of the first attempts to move to this level of disaggregation. The population is used a control variable for the different size of the NUTS3 regions in different countries.

${ }^{8}$ The dates of foundation of R\&D units in the JETRO database also show that production typically attracts $R \& D$, and not vice versa.

${ }^{9}$ There are 260 missing values in the independent variables.

${ }^{10} \mathrm{We}$ also used the total number of patents in the region (PAT) as the explanatory variable. The estimates did not change. 
${ }^{11}$ The result is computed by $\mathrm{dP}(\mathrm{Y}) / \mathrm{dX}$, where $\mathrm{dP}(\mathrm{Y})$ is the desired increase in the share of $\mathrm{R} \& \mathrm{D}$ over the total Japanese investments in the area, and $\mathrm{dX}$ is the change in the explanatory variables needed to obtain a certain $\mathrm{dP}(\mathrm{Y})$.

${ }^{12}$ These percentages correspond to different absolute numbers, depending upon the initial characteristics of each region.

${ }^{13}$ See: Bartlett (1986), Bartlett and Goshal (1989), Hedlund (1986), among the others.

${ }^{14}$ See: Casson, Pearce and Singh (1992). 